Portland State University

PDXScholar

\title{
Effects of Sex and Mycorrhizal Fungi on Gas Exchange in the Dioecious Salt Marsh Grass Distichlis Spicata
}

\author{
Kassandra Reuss-Schmidt \\ Portland State University \\ Todd N. Rosenstiel \\ Portland State University, rosensti@pdx.edu
}

Sally R. Rogers

Portland State University

Allie G. Simpson

Portland State University

Sarah M. Eppley

Portland State University, eppley@pdx.edu

Follow this and additional works at: https://pdxscholar.library.pdx.edu/bio_fac

Part of the Biology Commons, Environmental Microbiology and Microbial Ecology Commons, and the Environmental Sciences Commons

\section{Let us know how access to this document benefits you.}

\section{Citation Details}

Reuss-Schmidt, K., Rosenstiel, T. N., Rogers, S. R., Simpson, A. G., \& Eppley, S. M. (2015). Effects of Sex and Mycorrhizal Fungi on Gas Exchange in the Dioecious Salt Marsh Grass Distichlis spicata. International Journal of Plant Sciences, 176(2), 000-000.

This Article is brought to you for free and open access. It has been accepted for inclusion in Biology Faculty Publications and Presentations by an authorized administrator of PDXScholar. Please contact us if we can make this document more accessible: pdxscholar@pdx.edu. 
Int. J. Plant Sci. 176(2):141-149. 2015.

(C) 2015 by The University of Chicago. All rights reserved.

1058-5893/2015/17602-0004\$15.00～DOI:10.1086/679351

\title{
EFFECTS OF SEX AND MYCORRHIZAL FUNGI ON GAS EXCHANGE IN THE DIOECIOUS SALT MARSH GRASS DISTICHLIS SPICATA
}

\author{
Kassandra Reuss-Schmidt,* Todd N. Rosenstiel,* Sally R. Rogers,* Allie G. Simpson,* and Sarah M. Eppley ${ }^{1, *}$ \\ *Center for Life in Extreme Environments and Department of Biology, PO Box 751, Portland, Oregon 97207-0751, USA
}

Editor: Pamela K. Diggle

\begin{abstract}
Premise of research. In dioecious plant species, males and females often differ in physiology, and mycorrhizal fungal relationships are likely to influence these differences. However, few data are available on the potential role of mycorrhizal fungi in altering sex-specific physiology and population sex ratios of dioecious plant species.

Methodology. In this study, we measured leaf gas exchange in a multifactorial greenhouse experiment with and without mycorrhizal fungal additions and under field conditions in Distichlis spicata, a dioecious $\mathrm{C}_{4}$ salt marsh grass, displaying extreme spatial sex ratio variation.
\end{abstract}

Pivotal results. We found a significant interaction between gas exchange, plant sex, and mycorrhizal fungal infection. Specifically, females but not males had significantly lower transpiration rates and higher water use efficiency (WUE) in treatments with increased mycorrhizal fungi. Additionally, field data showed similar WUE between plants at female-majority sites and male-majority sites, despite significantly lower rates of net assimilation and stomatal conductance in plants at female-majority sites.

Conclusions. Our results suggest that the higher WUE associated with increased mycorrhizal fungi in female D. spicata plants may be an important physiological attribute enabling female success in the higher-stress saltwater environment contributing to the spatial segregation of the sexes observed in this dioecious species.

Keywords: dioecy, mutualism, photosynthesis, reproduction, spatial segregation of the sexes, water use efficiency.

\section{Introduction}

Understanding sex-specific physiology and how it varies with abiotic stress is key to understanding the role of physiology in reproductive allocation and the maintenance of sex ratio variation in dioecious plant species (Barrett and Hough 2013). However, sex-specific differences in physiology are not well understood in plants and vary widely among species (for review Dawson and Geber 1999; Nicotra et al. 2003; ÁlvarezCansino et al. 2010). For instance, in Silene latifolia, males have consistently higher rates of net assimilation and stomatal conductance than do females, and nutrient treatments do not appear to affect this result (Gehring and Monson 1994; Laporte and Delph 1996). Conversely, females in Sabina vulgaris have consistently higher net assimilation rates and water use efficiency (WUE) than do males (He et al. 2003). In other species, environmental stress causes sex-specific physiological differences to increase (e.g., Xu et al. 2008; Montesinos et al. 2012; Li et al. 2013), even in some cases where such differences do not occur under mesic conditions (Correia and Díaz Barradas 2000).

\footnotetext{
${ }^{1}$ Author for correspondence; e-mail: eppley@pdx.edu.
}

Manuscript received April 2014; revised manuscript received October 2014; electronically published December 19, 2014.
Sex-specific physiological differences have been associated with sex ratio variation in many plant species ( $\mathrm{Li}$ et al. 2007), as differences in physiology between males and females may lead to sex-specific mortality. In species exhibiting extreme sex ratio bias, including spatial segregation of the sexes (SSS), differences in physiology between the sexes have been found, and these differences often change along environmental gradients (Dawson and Bliss 1989; Dawson and Ehleringer 1993; Sánchez-Vilas and Retuerto 2009; Groen et al. 2010; SánchezVilas and Retuerto 2011). Ongoing climate change is altering both environmental gradients and the effects of sex-specific physiology and thus is predicted to alter sex ratios in many dioecious plant species (Hultine et al. 2013).

Despite these observations, remarkably little information is available on how sex-specific physiology in dioecious plants interacts with other biological components of the community, including mycorrhizal fungi, herbivory, and competition, and yet such interactions are likely to have direct effects on population sex ratios. In dioecious plant species, mycorrhizal fungi have previously been found to have significantly different effects on males and females (Varga and Kytöviita 2008; Varga 2010; Vega-Frutis et al. $2013 b$ for review). However, the effects of mycorrhizal fungi on plant sex-specific physiology are largely unexplored. Mycorrhizal fungi form symbiotic relationships with more than $80 \%$ of flowering plants (Lee et al. 2013), generally having a mutualistic relationship, although 
the relationship may break down into parasitism (Johnson et al. 1997; Hoeksema et al. 2010 for review). Fungi benefit mainly via carbohydrate gain from their plant hosts (Finlay and Söderström 1992). The benefit for plants may include increased nutrient uptake (often phosphorus uptake; Marschner and Dell 1994; Smith and Smith 2011), protection from drought stress (Auge 2001), and alleviation of saline stress (Evelin et al. 2009; Porcel et al. 2012 for review). Differences in physiology between male and female plants are likely to alter the costbenefit balance of these mutualistic relationships, as differences in a plant's photosynthetic rate may alter the availability of carbohydrates a plant has in excess to trade, and differences in a plant's nutrient or water needs may alter the benefit of trading for these limiting resources with the fungal partner. Thus, to understand the role of mycorrhizal fungi in dioecious plant populations, we need to understand how mycorrhizal fungi affect sex-specific plant physiology and how this might ultimately alter sex ratios via sex-specific mortality.

In this study, we examined sex-specific physiology in Distichlis spicata, a $\mathrm{C}_{4}$ salt marsh grass in which sex is genetically determined and that exhibits extreme sex ratio bias, resulting in SSS (Freeman et al. 1976; Eppley et al. 1998). In the D. spicata system, a difference in arbuscular mycorrhizal fungal (AMF) infection rate has been observed between male plants and female plants, with females showing infection 1.62.6 times higher than their male counterparts (Eppley et al. 2009). Majority-female D. spicata sites have substantially higher phosphorus levels (Eppley 2001; Eppley et al. 2009) and higher salt levels (Lazarus et al. 2011) and are inundated more often than are majority-male D. spicata sites (Eppley 2001). Particularly for female plants, with their high cost of reproduction, mycorrhizal fungi colonization in D. spicata may play a role in accessing phosphorus or in alleviating stress in the high-salt, low-freshwater sites.

To address the role of mycorrhizal fungi and nutrients in the D. spicata system, we examined leaf gas exchange parameters collected under greenhouse conditions under differing phosphorus and mycorrhizal fungi treatments and compared them to physiological measurements taken in the field. Females in dioecious and subdioecious species have generally been found to have higher photosynthetic rates than males, and this is likely to compensate for a higher cost of reproduction in females (Dawson and Ehleringer 1993; Laporte and Delph 1996; Tozawa et al. 2009). We thus hypothesized that females would have higher photosynthesis rates (net assimilation rates) than males under limiting resources (low phosphorus) and access to mycorrhizal fungi. If females have higher costs of reproduction than males, these costs are likely to include both carbohydrates and limited nutrients. Thus, with a higher cost of reproduction in females, females may need to increasingly trade carbohydrates for limiting resources (such as phosphorus or water) with their mycorrhizal fungal partners to support increased gas exchange and fruit production.

\section{Material and Methods}

\section{Study Species}

Distichlis spicata (L.) Greene (Poaceae) is a dioecious $\mathrm{C}_{4}$ salt marsh grass found in coastal salt marshes in North America and Mexico (Hitchcock 1971). The plants are wind pollinated (Hitchcock 1971), and their seeds are water dispersed (S. M. Eppley, personal observation). Distichlis spicata also spreads vegetatively via rhizomes and tillers (Hitchcock 1971). This study focuses on two D. spicata populations on the West Coast of the United States: one at Point Reyes National Seashore, Marin County, California, and one at Whalen Island, Tillamook County, Oregon. Distichlis spicata exhibits SSS in both populations (Eppley et al. 1998, 2009). Female-majority sites are significantly lower in elevation in the marsh than are malemajority sites (Eppley 2001). Also, in the Whalen Island population, higher concentrations of soil phosphorus have been observed in D. spicata female-majority habitats compared with male-majority habitats (Eppley et al. 2009), and similar results were found in a Tomales Bay, California, population (Eppley 2001) within $20 \mathrm{~km}$ of the Point Reyes population. Nitrogen soil content was not found to vary significantly between malemajority sites and female-majority sites and was therefore not examined in this study (Eppley 2000, 2001; Eppley et al. 2009). We measured mycorrhizal fungal colonization in the Whalen Island population in the field, and females were significantly more likely to be colonized by AMF than were males (Eppley et al. 2009). For the Point Reyes population, we measured mycorrhizal fungal colonization in the greenhouse and found similar results (Eppley et al. 2009), suggesting that even in a common garden environment the sexes respond differently to AMF.

\section{Greenhouse Experimental Design}

To test the effects of phosphorus levels and mycorrhizal fungi colonization on gas exchange under controlled conditions, male and female plants were grown in a research greenhouse at Portland State University (PSU). Distichlis spicata seeds were collected from the Point Reyes population in 2005 and grown in a greenhouse as stock plants. The sex of these plants was determined via sex-specific molecular markers (Eppley et al. 2009). In August 2010, 30 genetic individuals-15 males and 15 females-were randomly selected from the Point Reyes population being cultivated in the greenhouse. These 30 individuals were vegetatively cloned by planting $6 \mathrm{~cm}$ of rhizome possessing at least two nodes into $164 \mathrm{~mL}$ Cone-Tainers (Ray Leach Cone-Tainers Nursery, Canby, OR) that were filled with a mixture of one part nursery-grade sand to two parts Sunshine Mix \#2 (Sun Gro Horticulture, Vancouver, BC), creating four replicates of each genotype, one placed in each of the four treatment combinations. The soil was chosen as it was made of Canadian Sphagnum peat moss, coarse perlite, gypsum, and dolomitic limestone for water retention and had no nutrient additions, so that we could control nutrients. Additionally, a similar Sun Gro soil was used in a previous study, in which we found mycorrhizal fungal colonization was comparable between greenhouse samples and field samples (Eppley et al. 2009). The cones were placed in racks in trays, and each rack of cones stood in a tray where the cone bottoms were submerged in a nutrient solution consisting of $100 \mathrm{ppm}$ nitrogen and $100 \mathrm{ppm}$ potassium made using 4-0-0 nitrogen and 0-0-4 potassium liquid fertilizer (Nature's Nectar Hydroponic Nutrients, Kingston, ON) to supply macronutrients except phosphorus. Both the position of plants within the trays and tray 
placement in the greenhouse were randomized. Trays were randomized within the greenhouse twice a month, and new nutrient solution was added during randomization. No additional light was added, and daytime greenhouse temperatures were maintained between $18^{\circ}$ and $26^{\circ} \mathrm{C}$.

To examine the effects and interactions of sex, phosphorus level, and mycorrhizal fungi, the trial groups were divided into trays that differed in phosphorus and mycorrhizal fungi exposure. Using 0-4-0 phosphorus liquid fertilizer (Nature's Nectar Hydroponic Nutrients), plants were exposed to one of two levels of phosphorus, 60 or $10 \mathrm{ppm}$, which correspond to the higher and lower levels of phosphorus measured in female- and male-majority field sites, respectively.

Half of the plants in each of the high- and low-phosphorus treatments were subjected to one of the two mycorrhizal fungi treatments and half to the other treatment (resulting in four treatment combinations). For the mycorrhizal fungi treatments, either plants were inoculated with mycorrhizal fungi spore treatment or were treated with a sterile equivalent (control inoculum). Air-dried soil from male- and female-majority sites at Whalen Island was mixed to include the breadth of fungal spores in that population. Spores were collected from Whalen Island rather than Point Reyes (where the plants originated), as we no longer have access to Point Reyes, which is a federally protected site. The soil (with roots removed) was then either sterilized in an autoclave for the control inoculums or directly added to deionized water to make the mycorrhizal fungal inoculums. The control inoculum was sterilized to reduce the number of mycorrhizal fungal spores, potentially affecting the nutrient content; however, this inoculum was only a small proportion of the soil used in the experiment, as it was added to existing soil in which the plants were grown, and thus its effect on plant nutrition was likely to have been small. However, the sterilization would remove all microbial additions, including bacteria and other types of fungi, and thus the control treatment must be considered in this light. Plants were inoculated with $5 \mathrm{~g}$ of slurried soil from the respective treatments (mycorrhizal fungal inoculum or control inoculum) every other week to maintain high inoculum levels within the mycorrhizal fungal treatments.

\section{Greenhouse Data Collection}

In mid-February 2012, between 900 and 1700 hours, leaf gas exchange parameters were measured by utilizing a Li-Cor 6400XT portable photosynthesis system (Li-6400XT, Li-Cor, Lincoln, NE). Gas exchange parameters included net $\mathrm{CO}_{2}$ assimilation rate $(A$, a measure of mean light-saturated rate of photosynthesis), stomatal conductance $\left(g_{\mathrm{s}}\right)$, and transpiration rate $(E)$. Gas exchange parameters were measured with a 6- $\mathrm{cm}^{2}$ LED cuvette (LI-O2B) with cuvette conditions set at 2000 PAR $\mu \mathrm{mol}$ photons $\mathrm{m}^{-2} \mathrm{~s}^{-1}$ (as this is the light level at which saturation occurred; no photoinhibition was seen for any samples), a $\mathrm{CO}_{2}$ concentration controlled at $400 \mathrm{ppm}$ with an onboard mixer, and temperature matched to ambient conditions. Chamber humidity was monitored, and levels consistently fell within $55 \%-66 \%$ relative humidity. Four to six mature leaves from each plant were secured onto the chamber head and brought to their maximal rates of net assimilation at the given conditions; leaves typically reached steady state con- ditions within $10 \mathrm{~min}$ of enclosing within the cuvette. Intrinsic WUE was calculated as a ratio of net assimilation rate to transpirational water loss $(A / E)$. To determine total leaf area, the leaves were then harvested, photographed, and analyzed in ImageJ (Abramoff et al. 2004). Leaves harvested to measure leaf area were dried at $60^{\circ} \mathrm{C}$ in a drying oven for $48 \mathrm{~h}$, weighed, and later added to the shoot mass in the destructive harvest.

To account for other variables that might affect gas exchange, chlorophyll content and specific leaf area were measured in February 2012 to coincide with the gas exchange measures. Chlorophyll content was measured using a Minolta SPAD-2 leaf chlorophyll meter. Specific leaf area was determined by collecting 5 leaves from 15 different male and female plants not involved in this gas exchange experiment that were grown concurrently in the greenhouse. A different set of plants from the primary research plants was used because we did not want to alter the final biomass results, and plants were not harvested for biomass for another month (as this was part of a larger experiment). The leaves were dried at $60^{\circ} \mathrm{C}$ for $48 \mathrm{~h}$ and weighed. Area was again determined via photo analysis with ImageJ software.

A destructive harvest was carried out during the first week of March 2012 (72 wk after planting) to measure total biomass and to determine the plant root-to-shoot ratio. Roots were cleaned and mechanically separated from the shoot biomass. A random small portion of the root, taken from the entire root collection for each plant, was harvested in order to quantify AMF colonization rates. The remainder of the roots and shoots was then placed in a drying oven at $60^{\circ} \mathrm{C}$ and left for $48 \mathrm{~h}$. The respective portions were then weighed.

\section{AMF Colonization Analysis}

The portion of roots set aside for AMF colonization quantification was taken from storage at $4{ }^{\circ} \mathrm{C}$ and washed with tap water. Collected roots within a sample were stained with Trypan blue, following Koske and Gemma (1989). After staining, $501-\mathrm{cm}$ root segments from each plant were randomly chosen and mounted on slides. AMF colonization was quantified using the magnified intersection method of McGonigle et al. (1990). We were able to obtain colonization data on 112 of the 120 plants from the greenhouse experiment. We found that, although we tried to maintain our noninoculated treatment with no mycorrhizal fungi colonization, this treatment in fact had mycorrhizal fungal colonization, though to a lower degree than our inoculated treatment. Because we grew plants of noninoculated and inoculated treatments close to each other for over a year with plants submerged in water, cross contamination likely occurred from water spray among trays. Thus, we ended up with low and high mycorrhizal fungal treatments similar to those used by Botham et al. (2009) due to mycorrhizal fungal colonization of their noninoculated treatment. Our analysis of arbuscular mycorrhizal colonization between treatments showed that plants in the treatment inoculated with mycorrhizal fungal spores were significantly more likely to be colonized with arbuscules (inoculated plants $=4.1 \% \pm 0.7 \%$ arbuscular colonization vs. noninoculated plants $=2.3 \% \pm$ $0.5 \%$ arbuscular colonization; $F=4.69, P=0.03 ; N=112$, using a Welch's ANOVA due to unequal variance) and marginally significantly more likely to be colonized by all deter- 
minants of AMF, including hyphae, arbuscules, and vesicles (inoculated plants $=35.5 \% \pm 0.2 \% \mathrm{AMF}$ colonization vs. noninoculated plants $=29.2 \% \pm 0.2 \%$ AMF colonization; $F=3.38, P=0.07 ; N=112$ ), than plants in the noninoculated treatment. Male and female plants did not differ significantly in arbuscular colonization $(F=0.99, P=0.75$, using Welch's ANOVA) or in total measure of AMF colonization $(F=2.39, P=0.13)$. Similarly, we found no significant differences in arbuscular colonization $(F=0.19, P=0.66)$ or in total AMF colonization $(F=0.06, P=0.81)$ between phosphorus treatments.

\section{Field Data Collection}

To measure gas exchange in plants under field conditions, during the second week of July 2012, a field campaign to the Whalen Island site was undertaken to measure 32 plants. Daily high temperatures during this period were $19.0^{\circ} \pm 1.0^{\circ} \mathrm{C}$ and daily lows were $10.6^{\circ} \pm 1.1^{\circ} \mathrm{C}$, with no recorded precipitation (data from the Clovedale, OR, weather station within $10 \mathrm{~km}$ of the site; data from the National Climatic Data Center, National Oceanic and Atmospheric Administration). Previous work in this site determined that patches of D. spicata are extremely sex biased, with female-majority sites having sex ratios of $0.32 \pm 0.05 \mathrm{SE}$ and male-majority sites having sex ratios of $0.73 \pm 0.04 \mathrm{SE}$ (Eppley et al. 2009). As this population was flowering, male- and female-majority sites were determined via their inflorescences. To facilitate a comparison between the measurements in the greenhouse (which were nonflowering), only nonflowering individuals were used for gas exchange measurements. Measurements were taken between 1030 and 1730 hours with the same Li-Cor 6400XT unit and attachments as in the greenhouse experiment. The three uppermost fully expanded leaves of each plant were placed in the Li-Cor chamber head and measurements, including $A, g_{s}$, and $E$, were taken. Leaf cuvette chamber conditions were the same as those used in the greenhouse study, as temperature and humidity saturation levels were found to be similar. Intrinsic WUE was again calculated as a ratio of net assimilation rate to transpirational water loss. To determine total leaf area, the leaves used in field gas exchange were then harvested, photographed, and analyzed in ImageJ (Abramoff et al. 2004), and gas exchange parameters were corrected for total leaf area during each measurement.

\section{Data Analyses}

Gas exchange data from both the greenhouse and field plants were analyzed via ANOVA. In the greenhouse experiment, we determined the effects of sex, phosphorus treatment, mycorrhizal fungi treatment, and interactions among these effects on net assimilation rate, stomatal conductance, transpiration rate, and instantaneous WUE. For the field data, the same gas exchange measures were compared between malemajority sites and female-majority sites. All data conformed to the assumptions necessary to apply the ANOVA except for transpiration rate in the field experiment, which showed unequal variance until transformed $(1 / x)$. Significant differences among treatments were determined by post hoc analyses. When significant, hour and humidity level were included as covariates in the models for gas exchange. To determine whether mycorrhizal colonization differed between the sexes or treatments, we used ANOVA or Welch's ANOVA for cases when the variances were unequal. All analyses were conducted using JMP 10 (SAS Institute 2012).

\section{Results}

\section{Greenhouse Results}

In the greenhouse experiment, net assimilation rates were significantly greater in the high-phosphorus treatment compared with the low-phosphorus treatment but not significantly affected by sex, the mycorrhizal fungal treatment, or interactions between these factors (tables 1,2). On the other hand, stomatal conductance was marginally significantly affected by the interaction between sex and the mycorrhizal fungal treatment; stomatal conductance was not directly affected by sex, the mycorrhizal fungal treatment, or the phosphorus treatment. Transpiration rate was significantly affected by the interaction between sex and the mycorrhizal fungal treatment (table 1; fig. 1a), while WUE was significantly affected by the phosphorus treatment, the interaction between the mycorrhizal fungal treatment and the phosphorus treatment, and the interaction between sex and the mycorrhizal fungal treatment (fig. 1b). Biomass was significantly greater in the higher-phosphorus treatment compared with the lowerphosphorus treatment (tables 1, 2). Chlorophyll content and root-to-shoot ratio were significantly affected by the mycor-

Table 1

Effects of Sex, Mycorrhizal Fungi, and Phosphorus on Leaf Gas Exchange and Biomass for Greenhouse Plants

\begin{tabular}{|c|c|c|c|c|c|c|c|c|c|c|c|c|c|c|}
\hline & \multicolumn{2}{|c|}{$A$} & \multicolumn{2}{|c|}{$g_{\mathrm{s}}$} & \multicolumn{2}{|c|}{ E } & \multicolumn{2}{|c|}{ WUE } & \multicolumn{2}{|c|}{ Biomass } & \multicolumn{2}{|c|}{ Root: shoot } & \multicolumn{2}{|c|}{ Chlorophyll } \\
\hline & $F$ & $P$ & $F$ & $P$ & $F$ & $P$ & $F$ & $P$ & $F$ & $P$ & $F$ & $P$ & $F$ & $P$ \\
\hline Sex & .67 & .42 & .80 & .37 & .28 & .60 & .12 & .73 & .29 & .59 & .45 & .50 & 1.19 & .28 \\
\hline Phos. & 12.90 & .0005 & 1.63 & .20 & .58 & .45 & 18.96 & $<.0001$ & 15.63 & .0001 & .79 & .38 & 2.34 & .13 \\
\hline Myc. & .35 & .56 & .02 & .90 & .00 & .95 & .72 & .40 & .55 & .46 & 6.46 & .01 & 7.96 & .006 \\
\hline Phos. $\times$ sex & 1.66 & .20 & 1.29 & .26 & 1.64 & .20 & .00 & .97 & .02 & .88 & .00 & $\overline{95}$ & .59 &.$\overline{44}$ \\
\hline Phos. $\times$ myc. & 1.42 & .24 & .00 & .97 & .08 & .78 & 3.81 & .05 & .88 & .35 & .00 & .98 & 2.89 & .09 \\
\hline Sex $\times$ myc. & .61 & .44 & 3.77 & .06 & 4.33 & .04 & 5.85 & $\overline{.03}$ & .00 & .98 & 1.04 & .31 & .46 & .50 \\
\hline Sex $\times$ myc. $\times$ phos. & .88 & .35 & .48 & .49 & .13 & .72 & .01 & .92 & .06 & .80 & .21 & .65 & .00 & .98 \\
\hline
\end{tabular}

Note. ANOVAs were used to determine the effects of sex, mycorrhizal fungi infection treatment (Myc.), phosphorus treatment (Phos.), and the interaction between these on net assimilation rate $(A)$, stomatal conductance $\left(g_{s}\right)$, transpiration rate $(E)$, water use efficiency (WUE), total biomass, root-to-shoot ratio, and chlorophyll content in greenhouse-grown Distichlis spicata plants. Significant $P$ values are underlined. $N=120$. 
Table 2

Leaf Gas Exchange and Biomass Measures for Distichlis spicata Greenhouse Plants

\begin{tabular}{|c|c|c|c|c|c|c|}
\hline & Male & Female & Phos. + & Phos. - & Myc. + & Myc. - \\
\hline$A\left(\mu \mathrm{mol} \mathrm{CO} \mathrm{CO}_{2}^{-2} \mathrm{~s}^{-1}\right)$ & $18.70 \pm .61$ & $17.47 \pm .59$ & $\underline{19.49 \pm .63}$ & $16.68 \pm .53$ & $18.36 \pm .65$ & $17.81 \pm .56$ \\
\hline$g_{\mathrm{s}}\left(\mathrm{mol} \mathrm{H} \mathrm{O}_{2} \mathrm{~m}^{-2} \mathrm{~s}^{-1}\right)$ & $.17 \pm .01$ & $.16 \pm .01$ & $.17 \pm .01$ & $.16 \pm .01$ & $.17 \pm .01$ & $.17 \pm .01$ \\
\hline$E\left(\mathrm{mmol} \mathrm{H}_{2} \mathrm{O} \mathrm{m}^{-2} \mathrm{~s}^{-1}\right)$ & $3.02 \pm .10$ & $2.84 \pm .09$ & $2.99 \pm .11$ & $2.86 \pm .09$ & $2.94 \pm .11$ & $2.92 \pm .09$ \\
\hline WUE $\left(\mu \mathrm{mol} \mathrm{mol}^{-1}\right)$ & $6.30 \pm .14$ & $6.24 \pm .12$ & $6.66 \pm .14$ & $5.88 \pm .11$ & $6.35 \pm .13$ & $6.19 \pm .14$ \\
\hline Biomass (g) & $4.79 \pm .26$ & $4.59 \pm .28$ & $5.40 \pm .30$ & $3.98 \pm .18$ & $4.56 \pm .26$ & $4.82 \pm .27$ \\
\hline Root : shoot $\left(\mathrm{g}^{-1}\right)$ & $.94 \pm .03$ & $.97 \pm .04$ & $.93 \pm .03$ & $.97 \pm .03$ & $.90 \pm .03$ & $1.01 \pm .04$ \\
\hline Chlorophyll & $29.47 \pm .25$ & $28.91 \pm .39$ & $29.58 \pm .29$ & $28.80 \pm .44$ & $28 . \overline{47 \pm .36}$ & $2 \overline{9.91 \pm .37}$ \\
\hline
\end{tabular}

Note. Net assimilation rate $(A)$, stomatal conductance $\left(g_{\mathrm{s}}\right)$, transpiration rate $(E)$, water use efficiency (WUE), biomass, root/shoot, and relative leaf chlorophyll content, with means $( \pm S E)$ for male and female plants, plants in high- and low-phosphorus treatments (Phos.), and plants in the two mycorrhizal fungal treatments (Myc.). Underlined values indicate where measures significantly differed among phosphorus or mycorrhizal fungal treatments; values did not differ between sexes (when pooled across phosphorus and mycorrhizal fungal treatments). $N=$ 120.

rhizal fungal treatment (tables 1,2), with both lower in the mycorrhizal fungal treatment compared with the sterile treatment. There was no significant difference in specific leaf area between male and female plants $($ mean $=272.5 \pm 9.7$ and $272.1 \pm 14.3 \mathrm{~cm}^{2} \mathrm{mg}^{-1}$, respectively; $P=0.99$ ).

\section{Field Results}

A significant difference in net assimilation rate and moderately significant difference in stomatal conductance was observed between plants in male-majority sites and femalemajority sites (table 3; fig. 2). In both cases, male-majority sites showed higher rates than their female counterparts. Transpiration rate showed no significant differences between male-majority sites and female-majority sites (mean $=2.09 \pm$ 0.20 and $1.78 \pm 0.09 \mathrm{mmol} \mathrm{H}_{2} \mathrm{O} \mathrm{m}^{-2} \mathrm{~s}^{-1}$, respectively), and WUE also showed no significant difference between malemajority sites and female-majority sites (mean $=8.68 \pm 0.64$ and $7.61 \pm 0.60 \mu \mathrm{mol} \mathrm{mol}^{-1}$, respectively).

\section{Discussion}

We have previously shown that there are significant sexspecific differences in AMF infection in Distichlis spicata, with female plants showing infection 1.6-2.6 times higher than their male counterparts (Eppley et al. 2009). Here we have extended this work to examine sex-specific differences in leaf gas exchange as well as the role of AMF interactions in influencing carbon and water exchange in this $\mathrm{C}_{4}$ marsh grass species. Given the higher level of AMF infection previously observed in females, we hypothesized that females of D. spicata would maintain greater rates of net assimilation than males. However, as has been shown previously (Lazarus et al. 2011), we found no inherent differences in gas exchange measurements between male and female D. spicata plants under greenhouse conditions. Instead, our experimental results show a significant interactive effect of sex with AMF on transpiration rate and instantaneous WUE, with AMF substantially altering female values. Furthermore, in the field we found significant differences in gas exchange between plants in male- and femalemajority sites, yet despite these differences, we observed comparable levels of instantaneous WUE between sites. Taken to- gether, these results suggest that females of D. spicata positively respond to AMF infection by reducing $E$ and increasing WUE. These results may help to explain the previous observations of greater AMF infection in female plants, as reduced $E$ and enhanced WUE are both likely key traits for surviving the greater salinity of female-majority sites. Below we discuss the interaction between AMF and sex with respect to plant carbon-water trade-offs and the impacts of these trade-offs on the maintenance of biased population sex ratios and SSS in D. spicata.

\section{Sex-Specific Physiology and Mycorrhizal Fungi}

In dioecious plant species, the sexes have been shown to differ in mycorrhizal fungi colonization and to be affected differentially by mycorrhizal fungi (Varga 2010; Vega-Frutis et al. $2013 b$ for review), suggesting that males and females may differ in their cost-benefit relationship to these symbionts. However, our data are the first to show that the interaction between mycorrhizal fungi and dioecious plants affects sex-specific physiology, as the D. spicata females in the greenhouse gain an advantage in reduced $E$ and $g_{\mathrm{s}}$ and greater WUE with mycorrhizal fungi additions while males do not. While male WUE was not significantly affected by the mycorrhizal fungal treatment, females showed significantly higher WUE when treated with mycorrhizal fungi, and though not significant, females also displayed the lowest overall rates of transpiration in the presence of mycorrhizal fungi additions (fig. 1). Since the male and female plants were grown under identical greenhouse conditions, these results suggest a fundamental difference in the interactions between male and female plants and the mycorrhizal fungi. Specifically, females appear to benefit from mycorrhizal fungi partnerships, at least with respect to transpiration and WUE, while males do not. However, we cannot rule out the possibility that males of D. spicata derive some other benefit (e.g., nutrient acquisition) from mycorrhizal infection in exchange for carbohydrates. The addition of mycorrhizal fungi did significantly lower chlorophyll content in both sexes, suggesting there is a definite cost associated with forming these fungal relations in D. spicata, as is expected if the plants are providing carbohydrates to their fungal partners.

Given the interactions between AMF and sex-specific gas exchange we have observed, our results suggest that females may be able then to outperform males in the high-stress areas 
a

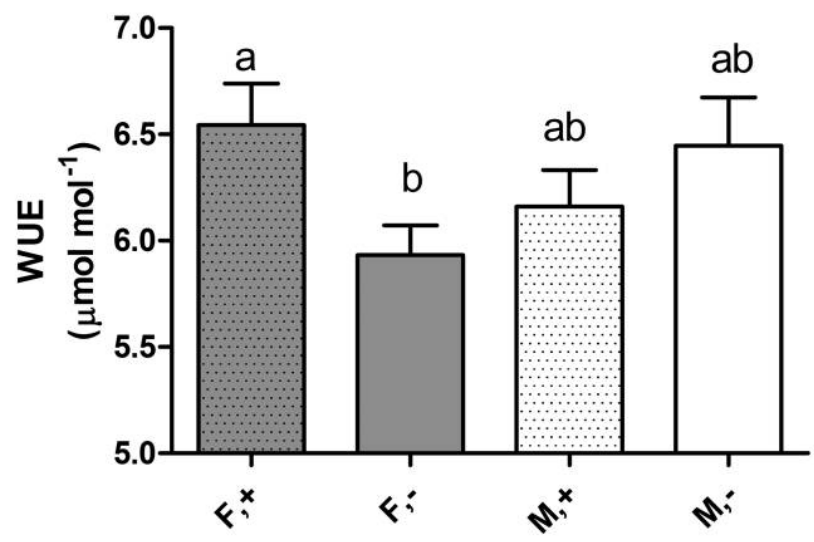

b

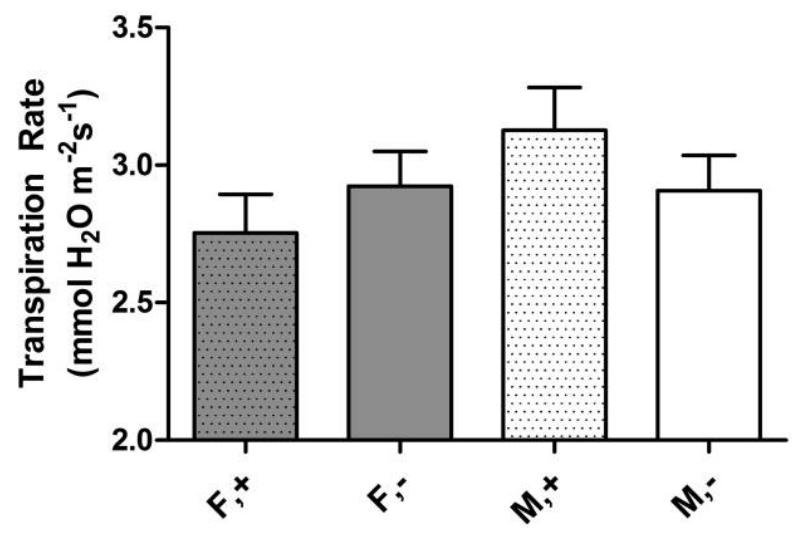

Fig. 1 For Distichlis spicata plants grown in the greenhouse, instantaneous water efficiency (WUE; mean $\pm \mathrm{SE} ; a$ ) and transpiration rate $(E$; mean $\pm \mathrm{SE} ; b)$ for female plants $(\mathrm{F})$ and male plants $(\mathrm{M})$ with (plus) and without (minus) the mycorrhizal fungi treatment. Different letters indicate that means are significantly different. For transpiration, the post hoc test was unable to distinguish significance among treatments despite a significant effect of sex by mycorrhizal fungal treatment in the ANOVA. $N=120$.

of the salt marsh by an increased interaction with AMF that facilitates lower rates of transpirational water loss and higher WUE. In previous research we found that females host greater mycorrhizal colonization than males (Eppley et al. 2009), potentially resulting in lower transpirational water loss and higher WUE for females. However, the benefits females may gain with AMF infection under field conditions likely come at a greater carbon cost (see field discussion below) yet may be necessary to successfully compete and dominate the saltier, lower-elevation sites in the marsh. Our results are consistent with numerous studies indicating enhanced WUE with AMF mycorrhizal as- sociations (Auge 2001; Miransari 2010) yet provide a novel perspective on the potential for sex-specific interactions of this widespread mutualism.

It should be noted that in the greenhouse our mycorrhizal fungi treatments were mild, as the treatments to which we added spores had high colonization while the ones to which we added only sterile soil had significantly lower but detectable colonization. More stringent treatment conditions, as were achieved previously in which the experiment was conducted for one-fifth of the time period (Eppley et al. 2009), might result in mycorrhizal fungi treatments that increase the differential effect of the treatments as difference in the costs and benefits of the mutualistic trade-off between the plants and fungi might increase. However, under field conditions these costs and benefits vary but are rarely zero, and our experiment was able to explore how variable investment in this relationship affected sex-specific gas exchange in this species. While our treatment changed potential mycorrhizal fungal interactions, it also presumably changed the interaction potential of other microbes, as we used sterilized inoculum as a control. Thus, variation in other microbes (including bacteria) between the sexes might have contributed to some of the observed results, and sex-specific differences in microbial colonization beyond mycorrhizal fungal colonization have been reported to occur in a variety of dioecious species (Vega-Frutis et al. 2013a for review). To date, much of the work on sex-specific nonmycorrhizal microbial differences in plants has been done in horticultural species, and future research should focus on how potential differences between the sexes affect microbial communities and how such communities might affect the stress physiology and evolutionary ecology of dioecious species.

\section{Sex-Specific Physiology and SSS}

SSS has been observed in more than 30 dioecious and subdioecious plant species (Bawa and Opler 1977; Bierzychudek and Eckhart 1988; Dawson and Bliss 1989; Iglesias and Bell 1989; Shea et al. 1993; Bertiller et al. 2002; Dudley 2006; Nuñez et al. 2008). When SSS occurs, it generally correlates to an environmental gradient, most typically elevation, moisture, or nutrient gradients (Bawa and Opler 1977; Dawson and Bliss 1989; Iglesias and Bell 1989; Shea et al. 1993; Bertiller et al. 2002; Dudley 2006; Nuñez et al. 2008), with males often in more nutrient-poor, stressful environments than females (Bierzychudek and Eckhart 1988; Dawson and Bliss

Table 3

Effects of Site Majority Sex on Leaf Gas Exchange for Field Plants

\begin{tabular}{lcc}
\hline & $F$ & $P$ \\
\hline$A$ & 6.10 & .02 \\
$g_{s}$ & 2.74 & .06 \\
$E$ & 4.91 & .16 \\
WUE & 14.18 & .32 \\
\hline
\end{tabular}

Note. One-way ANOVAs were used to compare net assimilation rate $(A)$, stomatal conductance $\left(g_{\mathrm{s}}\right)$, transpiration rate $(E)$, and water use efficiency (WUE) for Distichlis spicata plants between male- and female-majority sites. Significant $P$ values are underlined. $N=32$. 
a

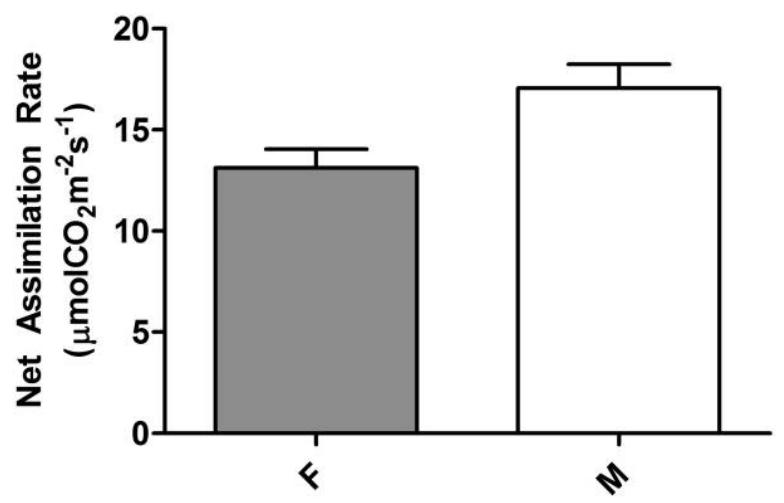

b $P=0.06$

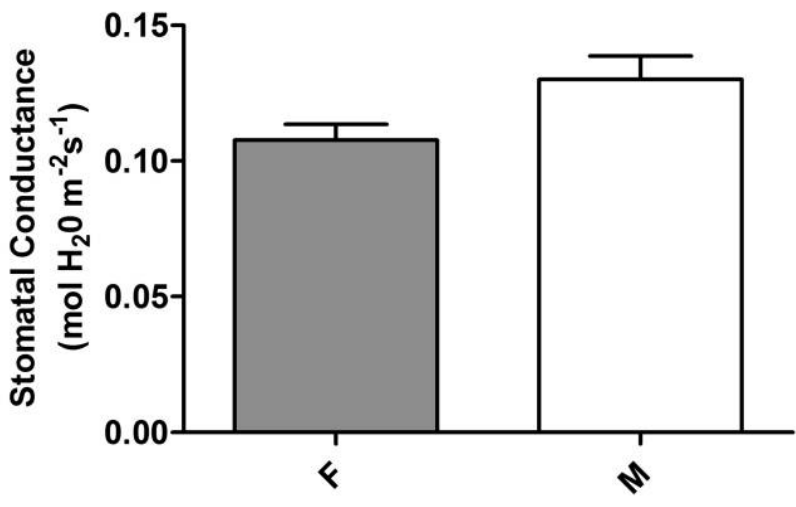

Fig. 2 For Distichlis spicata plants growing in the field, net assimilation rate $(A$; mean $\pm \mathrm{SE}$; $a)$ and stomatal conductance $\left(g_{s}\right.$; mean $\pm \mathrm{SE}$; b) as observed in female-majority (F) and male-majority (M) sites. $N=32$.

1989; Shea et al. 1993). Differences in environmental conditions between male-majority sites and female-majority sites in species with SSS suggest sex-specific differences in physiology that are adaptive to their respective microhabitats.

Unlike results from our greenhouse study, here we found significant differences in leaf gas exchange between plants from male- and female-majority sites of D. spicata in the field. Despite higher soil phosphorus content, females in femalemajority field sites showed lower net assimilation rates than males in male-majority sites, as well as depressed levels of stomatal conductance (fig. 2). These results were contrary to our expectations and are contrary to what has been found in other plant species with separate sexes. We hypothesized that females would have higher rates of photosynthesis than males, and females in dioecious and subdioecious species have been found to have higher photosynthetic rates than males (Dawson and Ehleringer 1993; Laporte and Delph 1996; Tozawa et al. 2009). One likely contributing factor to the differences we have observed in the greenhouse and the field that might explain the depression of net assimilation rates at female-majority sites is exposure to high concentrations of $\mathrm{NaCl}$ and inundation stress due to repeated inundation, as female-majority sites are lower in the marsh than male-majority sites. Though no difference in soil salinity was observed between male-majority sites and female-majority sites at the Whalen Island population, the level of saltwater inundation in the female dominant areas is much higher than that in male sites (Eppley 2001). Increased salt concentrations have been shown to depress photosynthetic rates in D. spicata (Tiku 1976; Kemp and Cunningham 1981; Warren and Brockelman 1989; Lazarus et al. 2011). Further, Kemp and Cunningham (1981) attributed a large portion of the observed depression in photosynthesis to stomatal closure, consistent with the lower stomatal conductance and depression in net assimilation observed here in our female plants. Another factor to explain the lower net assimilation rate in plants in female-majority sites compared with male-majority sites might be that female photosynthetic rates are depressed during re- production. This phenomenon has not been observed in this species but has been reported in Honckenya peploides, a subdioecious dune species that exhibits SSS (Sánchez-Vilas and Retuerto 2011). Although the plants we measured were not flowering, they were collected during the flowering season when nearby ramets were in flower. Water sharing between ramets has been observed in D. spicata (Alpert 1990), so it is probable that nonflowering shoots are sharing in the reproductive burden.

For D. spicata plants growing in the salt marsh, the environment is physiologically stressful, increasing in saltiness along a strong gradient. Because saltwater has low water potential, selection favors plants with high WUE efficiency in saltwater. In fact, many plants in salt marshes are $\mathrm{C}_{4}$ plants, including D. spicata, as $\mathrm{C}_{4}$ plants have greater WUE than do $\mathrm{C}_{3}$ plants (Sage and Monson 1999). In addition, lower stomatal transpiration is selected in saltwater environments, as transpiration in salt marshes often involves costly salt pumps (Long and Mason 1983); D. spicata has such pumps working to exclude sodium and chloride ions from D. spicata leaves, covering them with salt crystals (Hansen et al. 1976). The reduction in stomatal conductance (yet maintenance of WUE) we observed in female plants in the field is consistent with female plants' likely greater exposure to salinity.

Given our greenhouse results, it seems likely that AMF may be associated with maintaining WUE in females in the field, as female plants of D. spicata gained greater WUE with the addition of mycorrhizal fungi than males, consistent with a physiological adaptation to maintain water balance in the higher salt conditions found in majority-female sites. Similarly, with the addition of mycorrhizal fungi, females exhibited lower transpiration rates than did males, suggesting that they may be adapted to respond to these saltier conditions, minimizing reliance on costly salt pumps. The observation of no significant differences in instantaneous WUE between male and female plants of D. spicata under field conditions suggests that the abundance of mycorrhizal fungi associated with females' roots, 
as we have shown in previous work (Eppley et al. 2009), may be a key physiological strategy enabling greater access to water (and maintenance of WUE) in this saline habitat. As results of our study indicate a substantial interaction between AMF and sex-specific patterns of water exchange, this widespread halophyte species may provide a unique experimental system for contributing to ongoing efforts aimed at resolving the physiological and molecular basis for AMF alleviation of drought and salt stress (Auge 2001; Evelin et al. 2009; Ruiz-Lozano et al. 2012). Further, results from this work highlight the potential need for considering biotic interactions when evaluating pat- terns of sex-specific physiology and sex-specific plant functional traits (Reinhart et al. 2012).

\section{Acknowledgments}

We thank Scott Kiel for help in the lab and two anonymous reviewers for help with this manuscript. Research was supported by Portland State University, the Li-COR Environment Education Fund for undergraduate research, and the National Science Foundation (DEB 0743461).

\section{Literature Cited}

Abramoff M, P Magalhães, S Ram 2004 Image processing with Image J. Biophotonics Int 11:36-42.

$\rightarrow$ Alpert P 1990 Water sharing among ramets in a desert population of Distichlis spicata (Poaceae). Am J Bot 77:1648-1651.

$\rightarrow$ Álvarez-Cansino L, M Zunzunegui, MCD Barradas, MP Esquivias 2010 Gender-specific costs of reproduction on vegetative growth and physiological performance in the dioecious shrub Corema album. Ann Bot 106:989-998.

$\rightarrow$ Auge RM 2001 Water relations, drought and vesicular-arbuscular mucorrhizal symbiosis. Mycorrhiza 11:3-42.

$\rightarrow$ Barrett SCH, J Hough 2013 Sexual dimorphism in flowering plants. J Exp Bot 64:67-82

$\rightarrow$ Bawa KS, PA Opler 1977 Spatial relationships between staminate and pistillate plants of dioecious tropical forest trees. Evolution 31: 64-68.

$\rightarrow$ Bertiller MB, CL Sain, AJ Bisigato, FR Coronato, JO Ares, P Graff 2002 Spatial sex segregation in the dioecious grass Poa ligularis in northern Patagonia: the role of environmental patchiness. Biodivers Conserv 11:69-84.

$\rightarrow$ Bierzychudek P, V Eckhart 1988 Spatial segregation of the sexes in dioecious plants. Am Nat 132:34-43.

$\rightarrow$ Botham R, CL Collin, T-L Ashman 2009 Plant-mycorrhizal fungus interactions affect the expression of inbreeding depression in wild strawberry. Int J Plant Sci 170:143-150.

$\rightarrow$ Correia O, MC Díaz Barradas 2000 Ecophysiological differences between male and female plants of Pistacia lentiscus L. Plant Ecol 149:131-142.

$\rightarrow$ Dawson TE, LC Bliss 1989 Patterns of water use and the tissue water relations in the dioecious shrub, Salix arctica: the physiological basis for habitat partitioning between the sexes. Oecologia 79:332-343.

$\rightarrow$ Dawson TE, JR Ehleringer 1993 Gender-specific physiology, carbon isotope discrimination, and habitat distribution in boxelder, Acer negundo. Ecology 74:798-815.

Dawson TE, MA Geber 1999 Sexual dimorphism in physiology and morphology. Pages 175-216 in MA Geber, TE Dawson, LF Delph, eds. Gender and sexual dimorphism in flowering plants. Springer, Berlin.

$\rightarrow$ Dudley LS 2006 Ecological correlates of secondary sexual dimorphism in Salix glauca (Salicaceae). Am J Bot 93:1775-1783.

Eppley SM 2000 Intrapopulation sex ratio variation and sexual specialization in the dioecious grass Distichlis spicata. $\mathrm{PhD}$ diss. University of California, Davis.

$\rightarrow-2001$ Gender-specific selection during early life-history stages in the dioecious grass Distichlis spicata. Ecology 82:2022-2031.

$\rightarrow$ Eppley SM, CA Mercer, C Haaning, CB Graves 2009 Sex-specific variation in the interaction between Distichlis spicata (Poaceae) and mycorrhizal fungi. Am J Bot 96:1967-1973.

$\rightarrow$ Eppley SM, R O’Quinn, AL Brown 2009 New STS molecular markers for identification of sex in Distichlis spicata. Mol Ecol Notes 9:1373-1374. $\rightarrow$ Eppley SM, ML Stanton, RK Grosberg 1998 Intrapopulation sex ratio variation in the salt grass Distichlis spicata. Am Nat 152:659670.

$\rightarrow$ Evelin H, R Kapoor, B Giri 2009 Arbuscular mycorrhizal fungi in alleviation of salt stress: a review. Ann Bot 104:1263-1280.

Finlay R, B Söderström 1992 Mycorrhiza and carbon flow to the soil. Pages 134-160 in MF Allen, ed. Mycorrhizal functioning: an integrative plant-fungal process. Chapman \& Hall, New York.

$\rightarrow$ Freeman DC, LG Klikoff, KT Harper 1976 Differential resource utilization by the sexes of dioecious plants. Science 193:597-599.

$\rightarrow$ Gehring JL, RK Monson 1994 Sexual differences in gas-exchange and response to environmental-stress in dioecious Silene latifolia (Careyophyllaceae). Am J Bot 81:166-174.

$\rightarrow$ Groen KE, CR Stieha, PH Crowley, DN McLetchie 2010 Sex-specific plant responses to two light levels in the liverwort Marchantia inflexa (Marchantiaceae). Bryologist 113:81-89.

$\rightarrow$ Hansen DJ, P Dayanandan, PB Kaufman, JD Brotherson 1976 Ecological adaptations of salt marsh grass, Distichlis spicata (Gramineae), and environmental factors affecting its growth and distribution. Am J Bot 63:635-650.

$\rightarrow$ He WM, XS Zhang, M Dong 2003 Gas exchange, leaf structure, and hydraulic features in relation to sex, shoot form, and leaf form in an evergreen shrub Sabina vulgaris in the semi-arid $\mathrm{Mu}$ Us Sandland in China. Photosynthetica 41:105-109.

Hitchcock AS 1971 Manual of the grasses of the United States. Dover, New York.

$\rightarrow$ Hoeksema JD, VB Chaudhary, CA Gehring, NC Johnson, J Karst, RT Koide, A Pringle, et al 2010 A meta-analysis of contextdependency in plant response to inoculation with mycorrhizal fungi. Ecol Lett 13:394-407.

Hultine KR, KG Burtch, JR Ehleringer 2013 Gender specific patterns of carbon uptake and water use in a dominant riparian tree species exposed to a warming climate. Glob Change Biol 19:3390-3405.

$\rightarrow$ Iglesias MC, G Bell 1989 The small-scale spatial distribution of male and female plants. Oecologia 80:229-235.

$\rightarrow$ Johnson NC, JH Graham, FA Smith 1997 Functioning of mycorrhizal associations along the mutualism-parasitism continuum. New Phytol 135:575-585.

$\rightarrow$ Kemp PR, GL Cunningham 1981 Light, temperature and salinity effects on growth, leaf anatomy and photosynthesis of Distichlis spicata (L.) Greene. Am J Bot 68:507-516.

$\rightarrow$ Koske RE, JN Gemma 1989 A modified procedure for staining root to detect VA mycorrhizas. Mycol Res 92:486-505.

$\rightarrow$ Laporte MM, LF Delph 1996 Sex-specific physiology and sourcesink relations in the dioecious plant Silene latifolia. Oecologia 106: 63-72.

$\rightarrow$ Lazarus BE, JH Richards, PE Gordon, LR Oki, CS Barnes 2011 Plasticity tradeoffs in salt tolerance mechanisms among desert Distichlis spicata genotypes. Funct Plant Biol 38:187-198. 
$\rightarrow$ Lee EH, JK Eo, KH Ka, AH Eom 2013 Diversity of arbuscular mycorrhizal fungi and their roles in ecosystems. Mycobiology 41:121125.

$\rightarrow$ Li CY, G Xu, RG Zang, H Korpelainen, F Berninger 2007 Sex-related differences in leaf morphological and physiological responses in Hippophae rhamnoides along an altitudinal gradient. Tree Physiol 27:399-406.

$\rightarrow$ Li L, YB Zhang, JX Luo, H Korpelainen, CY Li 2013 Sex-specific responses of Populus yunnanensis exposed to elevated $\mathrm{CO}_{2}$ and salinity. Physiol Plant 147:477-488.

Long SP, CF Mason 1983 Saltmarsh ecology. Blackie, Glasgow.

Marschner H, B Dell 1994 Nutrient uptake in mycorrhizal symbiosis. Plant Soil 159:89-102.

$\rightarrow$ McGonigle TP, MH Miller, DG Evans, GL Fairchild, JA Swan 1990 A new method which gives an objective measure of colonization of roots by vesicular-arbuscular mycorrhizal fungi. New Phytol 115: 495-501.

Miransari M 2010 Contribution of arbuscular mycorrhizal symbiosis to plant growth under different types of soil stress. Plant Biol 12:563-569.

$\rightarrow$ Montesinos D, P Villar-Salvador, P Garcia-Fayos, M Verdú 2012 Genders in Juniperus thurifera have different functional responses to variations in nutrient availability. New Phytol 193:705-712.

$\rightarrow$ Nicotra AB, RL Chazdon, RA Montgomery 2003 Sexes show contrasting patterns of leaf and crown carbon gain in a dioecious rainforest shrub. Am J Bot 90:347-355.

$\rightarrow$ Nuñez CI, MA Nuñez, T Kitzberger 2008 Sex-related spatial segregation and growth in a dioecious conifer along environmental gradients in northwestern Patagonia. Ecoscience 15:73-80.

$\rightarrow$ Porcel R, R Aroca, JM Ruiz-Lozano 2012 Salinity stress alleviation using arbuscular mycorrhizal fungi: a review. Agron Sustain Dev 32:181-200.

$\rightarrow$ Reinhart KO, GWT Wilson, MJ Rinella 2012 Predicting plant responses to mycorrhizae: integrating evolutionary history and plant traits. Ecol Lett 15:689-695.

$\rightarrow$ Ruiz-Lozano JM, R Porcel, C Azcón, R Aroca 2012 Regulation by arbuscular mycorrhizae of the integrated physiological response to salinity in plants: new challenges in physiological and molecular studies. J Exp Bot 63:4033-4044.
Sage R, R Monson 1999 C $_{4}$ plant biology. Academic Press, San Diego, CA.

$\rightarrow$ Sánchez-Vilas J, R Retuerto 2009 Sex-specific physiological, allocation and growth responses to water availability in the subdioecious plant Honckenya peploides. Plant Biol 11:243-254.

$\rightarrow$ plant 2011 Reproduction reduces photosynthetic capacity in females of the subdioecious Honckenya peploides. Acta Oecol 37: 155-163.

SAS Institute 2012 JMP for Windows, release 10.0.0 ed. SAS Institute, Cary, NC.

$\rightarrow$ Shea MM, PM Dixon, RR Sharitz 1993 Size differences, sex ratio, and spatial distribution of male and female water tupelo, Nyssa aquatica (Nyssaceae). Am J Bot 80:26-30.

$\rightarrow$ Smith SE, FA Smith 2011 Roles of arbuscular mycorrhizas in plant nutrition and growth: new paradigms from cellular to ecosystem scales. Annu Rev Plant Biol 62:227-250.

$\rightarrow$ Tiku B 1976 Effect of salinity on the photosynthesis of the halophyte Salicornia rubra and Distichlis stricta. Plant Physiol 37:23-28.

$\rightarrow$ Tozawa M, N Ueno, K Seiwa 2009 Compensatory mechanisms for reproductive costs in the dioecious tree Salix integra. Botany 87: 315-323.

$\rightarrow$ Varga S 2010 Review: effects of arbuscular mycorrhizas on reproductive traits in sexually dimorphic plants. Span J Agric Res 8:S11-S24.

$\rightarrow$ Varga S, MM Kytöviita 2008 Sex-specific responses to mycorrhiza in a dioecious species. Am J Bot 95:1225-1232.

$\rightarrow$ Vega-Frutis R, MA Munguía-Rosas, S Varga, MM Kytöviita $2013 a$ Sex-specific patterns of antagonistic and mutualistic biotic interactions in dioecious and gynodioecious plants. Perspect Plant Ecol Evol Syst 15:45-55.

$\rightarrow$ Vega-Frutis R, S Varga, MM Kytöviita $2013 b$ Sex-specific interaction between arbuscular mycorrhizal and dark septate fungi in the dioecious plant Antennaria dioica (Asteraceae). Plant Biol 15:558-

$\begin{aligned} & 565 . \\ & \rightarrow \text { Warren RS, PM Brockelman } 1989 \text { Photosynthesis, respiration, and }\end{aligned}$ salt gland activity of Distichlis spicata in relation to soil salinity. Bot Gaz 150:346-350.

$\rightarrow$ Xu X, F Yang, X Xiao, S Zhang, H Korpelainen, C Li 2008 Sexspecific responses of Populus cathayana to drought and elevated temperatures. Plant Cell Environ 31:850-860. 